\title{
Tetraspanins as Organizers of Antigen-Presenting Cell Function
}

\section{OPEN ACCESS}

Edited by:

Annemiek van Spriel, Radboud University Nijmegen Medical Center, Netherlands

Reviewed by: Laura Santambrogio, Albert Einstein College of Medicine, United States

Bénédicte Manoury, Institut National de la Santé et de la Recherche Médicale (INSERM), France Mark Dexter Wright, Monash University, Australia

*Correspondence: Vera Rocha-Perugini verapfrp@gmail.com; Francisco Sánchez-Madria fsmadrid@salud.madrid.org

Specialty section: This article was submitted to Antigen Presenting Cell Biology, a section of the journal Frontiers in Immunology

Received: 18 January 2018 Accepted: 30 April 2018 Published: 23 May 2018

Citation:

Saiz ML, Rocha-Perugini V and

Sánchez-Madrid F (2018)

Tetraspanins as Organizers of Antigen-Presenting Cell Function.

Front. Immunol. 9:1074. doi: 10.3389/fimmu.2018.01074

\author{
Maria Laura Saiz ${ }^{1,2}$, Vera Rocha-Perugini, ${ }^{1,2 *}$ and Francisco Sánchez-Madrid 1,2,3* \\ 'Servicio de Inmunología, Hospital de la Princesa, Instituto de Investigación Sanitaria La Princesa, Madrid, Spain, \\ ${ }^{2}$ Vascular Pathophysiology Research Area, Centro Nacional de Investigaciones Cardiovasculares, Madrid, Spain, \\ ${ }^{3}$ CIBER Cardiovascular, Madrid, Spain
}

Professional antigen-presenting cells (APCs) include dendritic cells, monocytes, and B cells. APCs internalize and process antigens, producing immunogenic peptides that enable antigen presentation to $T$ lymphocytes, which provide the signals that trigger T-cell activation, proliferation, and differentiation, and lead to adaptive immune responses. After detection of microbial antigens through pattern recognition receptors (PRRs), APCs migrate to secondary lymphoid organs where antigen presentation to T lymphocytes takes place. Tetraspanins are membrane proteins that organize specialized membrane platforms, called tetraspanin-enriched microdomains, which integrate membrane receptors, like PRR and major histocompatibility complex class II (MHC-II), adhesion proteins, and signaling molecules. Importantly, through the modulation of the function of their associated membrane partners, tetraspanins regulate different steps of the immune response. Several tetraspanins can positively or negatively regulate the activation threshold of immune receptors. They also play a role during migration of APCs by controlling the surface levels and spatial arrangement of adhesion molecules and their subsequent intracellular signaling. Finally, tetraspanins participate in antigen processing and are important for priming of naïve T cells through the control of T-cell co-stimulation and $\mathrm{MHC}-\mathrm{II}$-dependent antigen presentation. In this review, we discuss the role of tetraspanins in APC biology and their involvement in effective immune responses.

Keywords: tetraspanins, tetraspanin-enriched microdomains, antigen-presenting cells, immune receptors, cell migration, antigen presentation

\section{INTRODUCTION}

Professional antigen-presenting cells (APCs), which include dendritic cells (DCs), monocytes/ macrophages, and B cells, are essential players of the immune system. Once an infection occurs, the innate immune system is stimulated, beginning the inflammation process to prevent the infection from spreading. Then, adaptive immune responses are required for the effective and specific clearance of the pathogen. This vital task lies on APCs, which operate at the interface between the innate and adaptive immunities. First, APCs detect foreign pathogens thanks to specialized receptors, known as pattern recognition receptors (PRRs). PRRs recognize conserved repeated motifs in microbial species, called pathogen associated molecular patterns (PAMPs), and enable APCs to discriminate between self and non-self (1). After engulfment of exogenous pathogens, APCs use their unique machinery to break down molecular antigens into small peptides and present a representative repertoire of these through a specialized immune receptor, namely, the major histocompatibility complex class II (MHC-II) molecule. This process triggers APC activation and maturation, with 
upregulation of surface expression of MHCII and co-stimulatory molecules. APC migration from peripheral tissues to secondary lymphoid organs is a key step for the generation of proper adaptive immunity, since antigen presentation to naïve T lymphocytes by APCs takes place primarily in secondary lymphoid organs (2). DCs have been extensively characterized and different subsets have been described $(3,4)$. Moreover, these cells precisely alternate their sentinel capacities with their antigenic presentation properties to favor antigen detection and migration, and antigen processing and presentation.

Tetraspanins belong to a family of small proteins $(20-30 \mathrm{kDa})$ that contain four transmembrane regions spanning the plasma membrane. They also share other structural features: a small and a large extracellular loop with conserved residues, and short $\mathrm{N}$ - and C- terminal tails (5). In humans and mice, 33 tetraspanin members have been identified. These proteins are widely distributed in cells and tissues. Some of them are ubiquitous (CD81, CD82, CD9, or CD63), whereas others have a tissue-restricted expression (CD37 or CD53 in immune cells) (6). Tetraspanins do not have the characteristics of prototype membrane receptors. They have small cytoplasmic tails that lack known motifs involved in signal transduction (5), and there are only few reports claiming tetraspanin ligands (7). Instead, tetraspanins function as molecular organizers of multimolecular membrane complexes, which facilitate signal transduction processes (8). Through the association with proteins and lipids, they organize specific membrane microdomains with a particular composition and detergent-solubilization properties, conforming the so-called tetraspanin-enriched microdomains (TEMs) $(9,10)$. TEMs are distinct from other well-known membrane domains, like lipid rafts, caveolae, and GPI-linked protein nanodomains (10).

Early studies using biochemical approaches have shown that TEMs follow a hierarchical network of associations based on the strength of the interactions $(5,9)$. The first level comprises the direct and specific interaction of a tetraspanin with its protein partner and is resistant to strong detergent conditions. The second level is characterized by interactions between tetraspanins. These interactions are more labile, resistant to mild detergents, and regulated by palmitoylation. Cutting edge fluorescence microscopy techniques, as single-molecule tracking, phasorFLIM-FRET and super-resolution microscopy, have more recently demonstrated that TEM organization and composition is highly dynamic (10-14). Accordingly, several studies have suggested that TEM composition can differ between cells. Through the organization of TEMs, tetraspanins regulate the function of their associated partners, finely tuning a breadth of biological processes. They may have overlapping functions in some cases or can have unique roles or even opposing functions. Their importance for several pathological and physiological processes has been discussed in detail elsewhere (15-22).

Tetraspanins have been widely studied in the mammalian immune system, and thanks to the generation of tetraspanin knockout mice a deeper comprehension is being achieved. Interestingly, the existence of tetraspanins in the innate immune system of invertebrates and non-mammalian vertebrates has also been described. Marine gastropod mollusks show ubiquitous expression of CD63 and Tspn33, which are upregulated upon different immune stimulation challenges, like toll-like receptor (TLR) ligands, bacteria or viral infection (23). Similarly, CD9 expression is induced in lamprey fish after LPS stimulation (24), or in turtles after bacterial infection (25). CD37 expression is highly increased in Atlantic salmons after a secondary viral infection (26). Conversely, treatment with several immune stimulators downregulate CD9, CD53, and CD63 expression in leukocytes from teleost fishes $(27,28)$. The study of the innate defense mechanisms in non-mammalian vertebrates can give additional hints for the comprehension of vertebrate innate immunity. In mammals, tetraspanins are master regulators of APC function, mediating the crosstalk between the immunogenic environment and APCs, and the interplay between innate and adaptive immune cells.

Herein, we will review the function of tetraspanins in regulating each step of APC function: at the cellular level, by modulating clustering and trafficking of immune receptors; during the process of APC migration, and finally during MHC-II-dependent antigen presentation. We will also discuss the growing evidence on tetraspanins as markers of specific DC subsets.

\section{Tetraspanins, Negative Regulators of PRRs}

Recognition and uptake of microbial antigens by APCs is mediated by PRRs, which bind conserved pathogen structures known as PAMPs (1). Membrane-bound PRRs include TLRs, C-type lectin receptors (CLRs), scavenger receptors (SRs) and NOD-like receptors. The efficiency of antigen recognition greatly depends on the supramolecular organization of PRRs at the APC surface, and tetraspanins play an important role in this process (Figure 1).

Toll-like receptors multimerization at the APC surface promotes the recruitment of signaling molecules (29), a process influenced by the inclusion of TLRs and associated co-receptors into TEMs. LPS stimulation triggers TLR-4 and CD81 co-clustering in peripheral blood monocytes (30). How CD81 regulates TLR-4 signaling has not been assessed; however, it has been shown that CD9 restricts LPS-induced macrophage activation and TNF- $\alpha$ production by preventing the TLR-4 co-receptor CD14 localization into lipid rafts (Figure 1). Through this mechanism, CD9 deficiency in mice enhances macrophage infiltration and lung inflammation after in vivo intranasal LPS administration (31). In DCs, bacterial antigens can be recognized by TLR-dependent pathways, sensing cell surface or endosomal antigens, and by cytosolic pathways, like the cytosolic sensor stimulator of IFN genes (STING) (32). Interestingly, CD81 negatively regulates STING/ IFNAR signaling through its interaction with Racl and the inhibition of STAT- 1 activation, thus leading to reduced TNF- $\alpha$ and NO production by inflammatory monocytes and DCs (Figure 1). As a consequence, CD81 deficient mice are protected against systemic Listeria monocytogenes infection (33).

Among the CLRs, Dectin-1 specifically recognizes $\beta$-glucans in fungal cell walls and is important for efficient immune response against fungi (34). Dectin-1 associates with tetraspanins CD37 and CD63 at the membrane of APCs when using CHAPS 1\% $(35,36)$, a mild detergent extraction condition that only keeps third level molecular interactions within TEMs $(7,10)$. Dectin-1 direct association with CD37 was however observed in transfected HEK293 cells when using Triton X-100 1\%, which preserves 


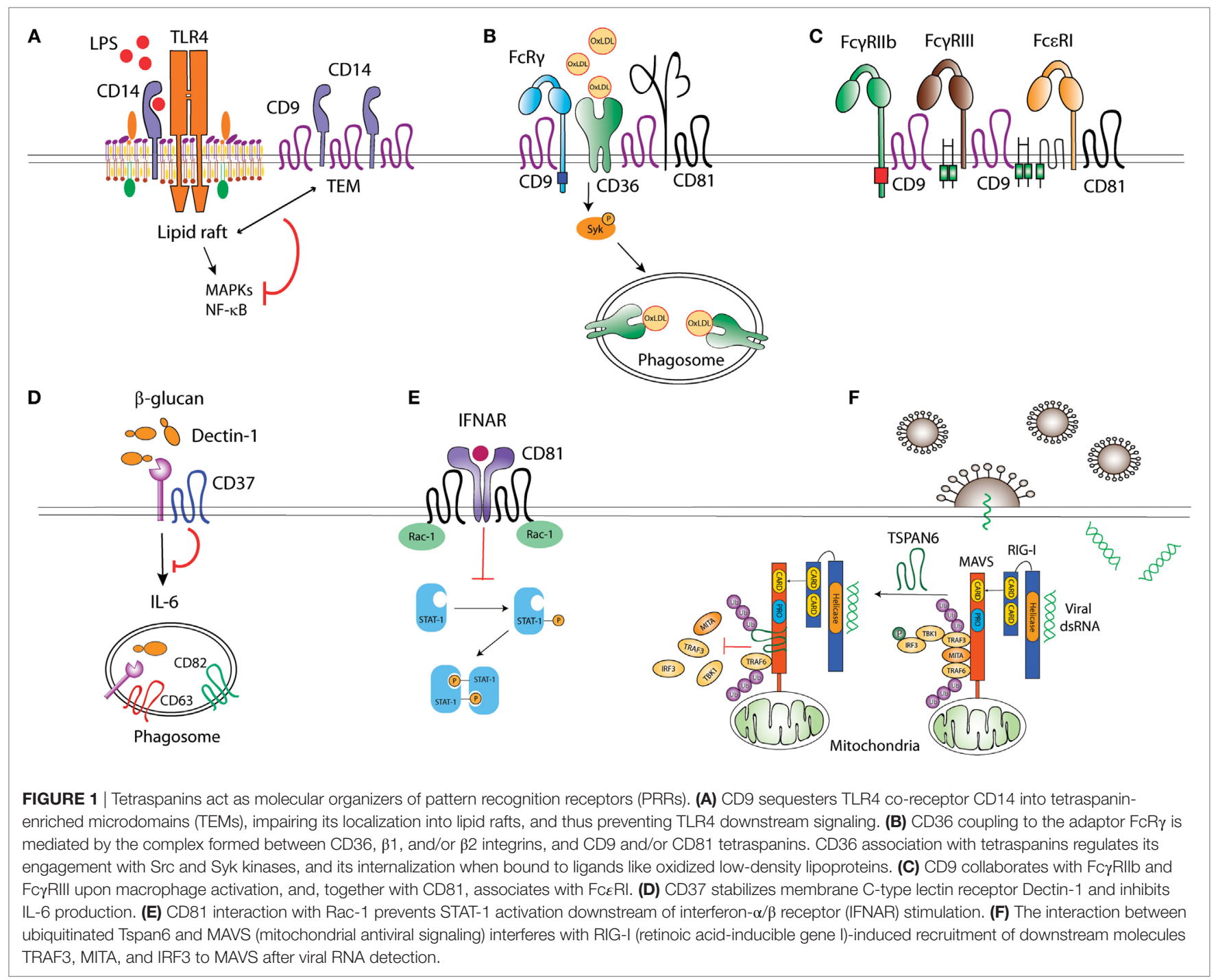

tetraspanin-partner primary complexes, but not in B cells (36), indicating that this interaction could be affected by other proteins expressed on APCs or that it is dynamically dependent on the cell activation status. CD37 stabilizes Dectin-1 surface expression and impairs its internalization, and Dectin-1-mediated TNF- $\alpha$ and IL-6 production in response to yeast cell walls (36) (Figure 1). Accordingly, $\mathrm{CD} 37^{-1-}$ mice are protected against systemic Candida albicans infection, producing high levels of IL-6 and specific IgA antibodies (37). On the other hand, CD37 mRNA expression positively correlates with Dectin-1 and IL- 6 mRNA in brains of mice infected with Toxoplasma gondii (38); however, further studies are necessary to evaluate this effect at the protein level and if there is any causal relationship. CD63 also seems to cooperate with Dectin-1 during yeast phagocytosis by human monocyte-derived DCs (MoDCs) (35), being specifically recruited to phagosomes containing Cryptococcus neoformans (39) in a process dependent on acidification and thought to be required for tethering the antigen-loading machinery together.

CD36 is a SR that recognizes proteinaceous or lipidic antigens from microbes, or self-ligands. In mouse macrophages, CD81 and CD9 are required for CD36 internalization after binding to oxidized low-density lipoprotein (oxLDL) ligands $(40,41)$. CD9 would be important for signaling in response to oxLDL, since oxLDL uptake and subsequent JNK phosphorylation are impaired in $\mathrm{CD}^{-1-}$ macrophages (40). Moreover, CD9 and CD81-dependent scaffolding of CD36, and $\beta 1$ and $\beta 2$ integrins in membrane multimolecular complexes is essential for CD36 association with FcyR (Fc receptor for IgG) and with Src and Syk kinases; and for its subsequent antigen uptake (41) (Figure 1). CD9 is also associated with the scavenger-like receptor CD5, which recognizes $\beta$-glucans expressed on fungi (42), although there is no experimental evidence about the functional implications of this interaction.

Pathogens can be opsonized with IgGs produced in response to microbial invasion, and recognized by Fc $\gamma$ Rs associated with PRRs. This combined stimulation triggers cytokine production and pathogen-specific innate immune responses. FcyRs seem to be included in TEMs in phagocytic cells. CD9 antibody cross-linking, but not Fc fragment alone, stimulates intracellular signaling dependent on Fc $\gamma$ RIIB and Fc $\gamma$ RIII, thus promoting mouse macrophage 
activation (43). Antibody cross-linking of tetraspanin CD82 enhances FcR-dependent activation of intracellular signaling in human monocytic cell lines (44). Importantly, IgG-opsonized HIV-1 particles are targeted to TEMs in endosomes of immature DCs (45). Other Fc receptors are also associated with TEMs, as the FceRI (Fc receptor for IgE), which is a molecular partner of CD9 and CD81 in human monocytes and skin-derived DCs (46) (Figure 1). The importance of TEMs as organizers of FcERI signalosome in mast cells has been recently reviewed elsewhere (47).

Tetraspanins can also regulate signaling of cytoplasmic PRRs, like the RIG-I-like receptors (RLRs). RLRs recognize viral RNA and trigger signaling pathways that induce type I IFN responses (48). In the presence of viral RNA, ubiquitination of human tetraspanin 6 (Tspn6) promotes its interaction with RIG-I, MDA5, and mitochondrial antiviral signaling (MAVS) signalosome, impairing the activation of IFN-stimulated response element (ISRE), NF- $\kappa \mathrm{B}$, and IFN- $\beta$ promoters (49) (Figure 1).

In summary, increasing evidence shows that tetraspanins usually act as negative regulators of PRR clustering and/or signaling. Thus, tetraspanins constitute key players to avoid uncontrolled immune responses, which are harmful to the host.

\section{Tetraspanins Tightly Control APC Migration}

Leukocyte migration is of fundamental importance for the efficient development of immune responses against pathogens. Innate immune cells capture antigens in peripheral tissues and then migrate to secondary lymphoid organs where antigen presentation to T lymphocytes takes place. Immune cells can also migrate out of the bloodstream toward the inflammation site, where adaptive immune responses occur (Figure 2). Thus, leukocytes modify their adhesive properties depending on the immune scenario (50). Innate immune cells usually need inflammation signals to initiate migration, whereas naïve lymphocytes efficiently migrate to secondary lymphoid organs, and after activation signals acquire specific migratory patterns. Tetraspanins have emerged as key regulators of cell migration, since they modulate the function of proteins involved in cell-cell adhesion, cell-ECM (extracellular matrix) adhesion, cytoskeletal protrusion/contraction, and proteolytic ECM remodeling. Indeed, tetraspanins associate with integrins, cadherins, members of the Ig superfamily, signaling molecules like Rac and Rho GTPases, and matrix metalloproteinases (MMP); regulating their membrane compartmentalization, intracellular trafficking, and proteolytic activity. Most of the information on tetraspanin regulation of cell migration comes from studies with adherent and tumor cells and has been reviewed in detail $(20,51)$. In this section, we will delineate the importance of tetraspanins for migration and extravasation of APCs.

Early studies employed cross-linking with monoclonal antibodies (mAbs) to investigate the role of tetraspanins in immune cell migration. Human MoDC in vitro migration toward MIP-5 and MIP- $1 \alpha$ chemokines was increased by the treatment with mAbs against CD9, CD63, CD81, or CD82 (35). These chemokines are

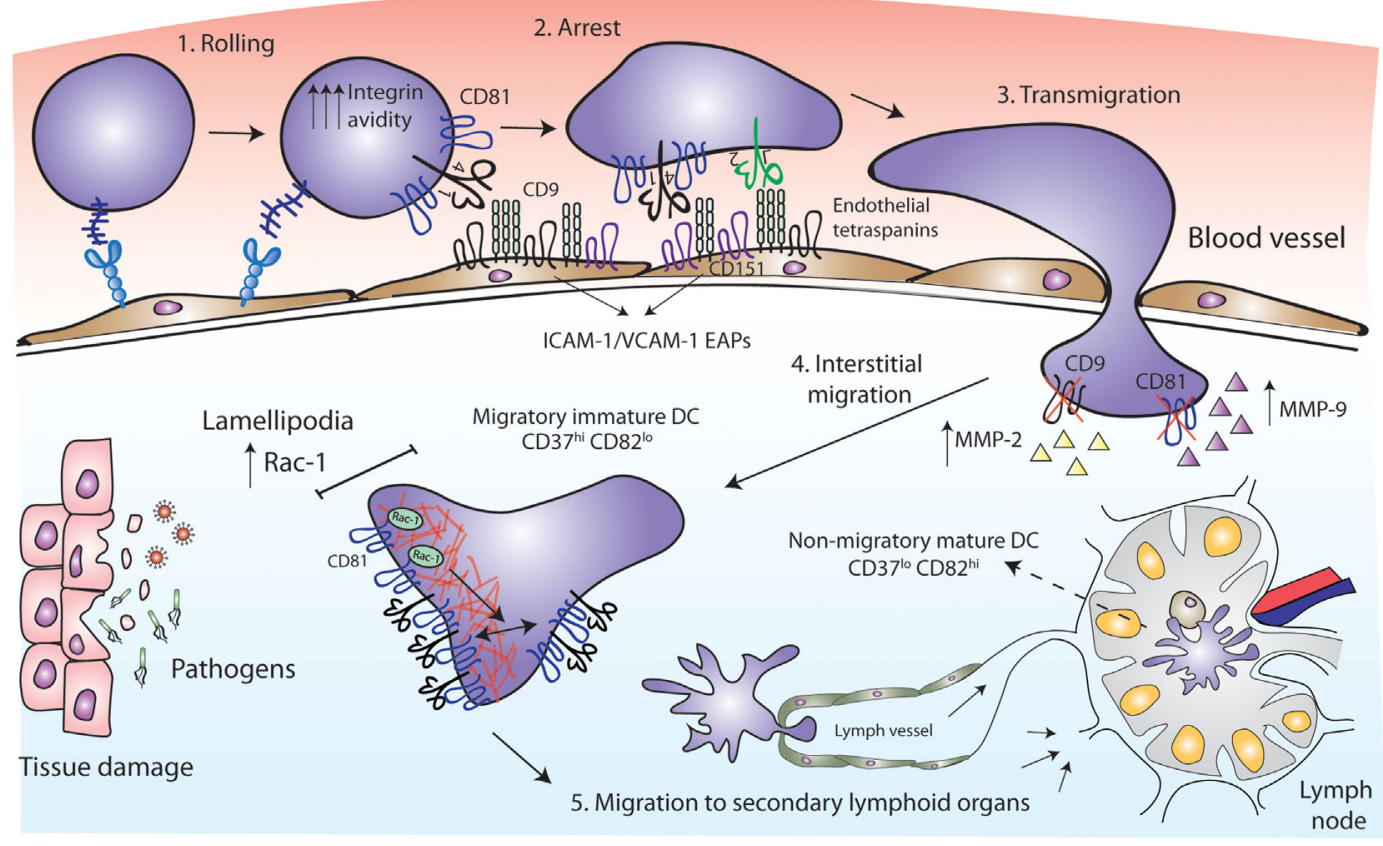

FIGURE 2 | Tetraspanins act as key players in antigen-presenting cell (APC) migration. CD81 facilitates rolling and arrest under shear flow, increasing the avidity of VLA-4 integrin. Tetraspanins CD9 and CD151 congregate the endothelial adhesion receptors (ICAM-1 and VCAM-1) in clusters called endothelial adhesive platforms, thus controlling their adhesive properties and leukocyte extravasation. CD9 and CD81 deficiency results in an increase of MMP-2 and MMP-9 metalloproteinases production and activity, required for interstitial migration. Once in the tissue, CD81 tetraspanin controls cell migration via Rac-1-dependent mobilization of preformed integrin clusters at the leading edge and contributes to the formation of lamellipodia. While migratory immature dendritic cells (DCs) are $\mathrm{CD} 37^{\mathrm{hi}}$ and $\mathrm{CD} 82^{\mathrm{lo}}$, mature DCs at the lymph nodes are CD37 ${ }^{\mathrm{lo}} \mathrm{CD} 82^{\mathrm{hi}}$, and display reduced migratory capacity and efficient antigen presentation machinery. 
strong chemoattractants required for the recruitment of inmature DCs to the surrounding tissue at the sites of injury $(52,53)$. After antigen capture, DCs mature, lose their responsiveness to inflammatory chemokines and express CCR7 $(54,55)$. CCR7 is the receptor for CCL19 and CCL21, which are chemokines highly present in lymphoid T-cell zones of secondary lymphoid organs (56), where DCs home to present their processed antigen to $\mathrm{T}$ lymphocytes. Opposite to that observed with MoDC migration toward MIP-5 and MIP- $1 \alpha$, the same mAb against CD81 (clone JS-81) or a CD81 ligand [the Hepatitis C Virus E2 envelope glycoprotein (57)] inhibited MoDC migration in response to CCL21 in vitro (58). These contradictory results could be due to different chemokine stimuli or to technical issues. Subsequent studies were all in line with a positive role for tetraspanins in cell migration. Monocyte transmigration across brain endothelial cell monolayers was significantly inhibited by an anti-CD9 $\mathrm{mAb}$ and several anti-CD81 mAbs, in both rodent and human in vitro models, by acting on the leukocyte side and on endothelial tetraspanins (59, 60). Accordingly, CD81 mAb (clone Eat2) administration reduced spinal cord inflammation in vivo, alleviating autoimmune encephalomyelitis (EAE) (59). Ly6C ${ }^{+}$monocytes, which can derive in MoDCs (61), are key determinants for Th17 differentiation in the EAE mouse model $(62,63)$. Moreover, since ICAM- 1 and VCAM-1 adhesion molecules are the ligands of leukocyte integrins Mac- $1(\alpha \mathrm{M} \beta 2)$ and LFA-1 ( $\alpha \mathrm{L} \beta 2)$ (for ICAM-1) and VLA-4 ( $\alpha 4 \beta 1$ ) (for VCAM-1), we must emphasize the importance of endothelial tetraspanins as organizers of ICAM-1 and VCAM-1 containing docking structures during leukocyte extravasation $(11,64)$. Importantly, loss-of-function studies have demonstrated that CD81 is essential for cell rolling, arrest, and migration. In both monocytic cell lines and mouse primary splenocytes, CD81 facilitates rolling and arrest under shear flow, increasing the avidity of integrin VLA-4 (65) (Figure 2). The link between tetraspanins and MMP during immune cell migration has also been investigated. Bone marrow-derived macrophages (BMDMs) from CD9 and CD81 double deficient mice show reduced motility, through a mechanism dependent on the regulation of MMP-2 and MMP-9 expression and activity (Figure 2). Interestingly, CD81 and CD9 double deficient mice spontaneously develop pulmonary emphysema, with elevated numbers of alveolar macrophages and increased MMP activity (66). A similar increase in MMP-2 and MMP-9 production and activity was observed in BMDMs from CD9-deficient mice, which showed decreased macrophage motility with an increase in macrophage infiltration after intranasal administration of LPS (31).

It is important to mention that DC motility behavior depends on the environmental context. DC migration on two-dimensional (2D) surfaces, like endothelial cell surfaces of the circulatory system, require adhesive forces and integrin functionality; whereas migration in three-dimensional (3D) environments, as interstitial ECM, is ameboid and less adhesive, and largely driven by cytoskeletal deformability (67-69). Importantly, tetraspanins fine-tune DC migratory capabilities by tightly controlling Rac1 and RhoA spatiotemporal activation. CD81 controls the migration of MoDCs, by regulating the formation of lamellipodia, and the mobilization of preformed integrin clusters at the leading edge of migratory cells (70). This tetraspanin is essential for the formation of actin protrusions through a mechanism dependent on its interaction with the small GTPase Rac-1 (70, 71) (Figure 2). Integrin adhesiveness and lamellipodia formation are required for DCs migration on $2 \mathrm{D}$ surfaces, thus this kind of migration is impaired in the absence of CD81. However, CD81 is not required for DCs migration within $3 \mathrm{D}$ collagen scaffolds, corresponding with unaffected Rho-A activity (70) and pointing out the differential molecular requirements of DCs migration. CD37 also promotes Rac-1 activation, while CD82 inhibits RhoA (72). Consequently, CD37 deficient DCs have impaired migration from the skin to the draining lymph nodes invivo, and reduced exvivo DC migration in response to CCL19(73). CD82 deficient DCs display the opposite phenotype (72). Absence of CD37 in BMDCs also reduces adhesion to fibronectin under low shear flow, and cell spreading (73), while CD82 deficiency increases DC spreading (72). Thus, CD $37^{\text {hi }} \mathrm{CD} 82^{\text {lo }}$ DCs would correspond to immature cells, showing increased migration and reduced capacity to activate naïve $\mathrm{T}$ cells, while $\mathrm{CD} 37^{\mathrm{lo}} \mathrm{CD} 82^{\text {hi }} \mathrm{DCs}$ would have an activated phenotype, being less motile and endowed with the proper presentation machinery to efficiently activate naïve $\mathrm{T}$ cells (72) (Figure 2). It is becoming increasingly clear that through the regulation of cytoskeletal rearrangement, integrins, and signaling molecules, tetraspanins constitute key players in APCs migration.

\section{MHC-II Trafficking and Antigen Presentation Take Place Within TEMs}

Upon their arrival to the lymph nodes, DCs transfer the information collected at peripheral tissues to $\mathrm{T}$ lymphocytes triggering adaptive immune responses. This process of antigen presentation is mediated by MHC-II molecules, which are able to stably bind to antigenic peptides, and then present these fragments of exogenous proteins to effector T lymphocytes. MHC-II is expressed on professional APCs and associates with several tetraspanins, including CD9, CD37, CD53, CD81, and CD82, at the surface of APCs (74-76). It has been suggested that different tetraspanins may play a role in MHC-II clustering (Figure 3). CD37 negatively regulates $\mathrm{MHC}$-II clustering, thus limiting antigen presentation by mouse splenic CD11c ${ }^{+}$DCs. CD37 knock-out splenic DCs show increased T-cell stimulatory capacity, by a mechanism strictly dependent on peptide-bound MHC-II signals (77). CD81 and CD9 co-immunoprecipitate with I-A MHC-II molecules in mouse BM-derived DCs and B blasts, and I-A/I-E heterologous multimerization is reduced in CD9-deficient BM-derived DCs (78). However, functional analyses were not performed in the study of Unternaehrer and collaborators. Another study has also suggested that MHC-II, together with HLA-DM and CD86, was included in TEMs containing tetraspanins CD9, CD63, CD81, and CD82 (79). This study was performed using the CDw78 antibody, which recognizes a specific determinant on an MHC-II subpopulation. However, this biochemical analysis of MHC-II multimerization was performed using mild detergent conditions (CHAPS 1\%). It was later demonstrated that CD9 and CD81 co-immunoprecipitation with MHC-II I-A/I-E multimers only occurs under these mild detergent conditions (80), not being observed when using more stringent conditions (Triton X-100). Thus, deficiency in CD9 or CD81 does not affect MHC-II clustering at the surface of mouse BM-derived DCs, while surface 


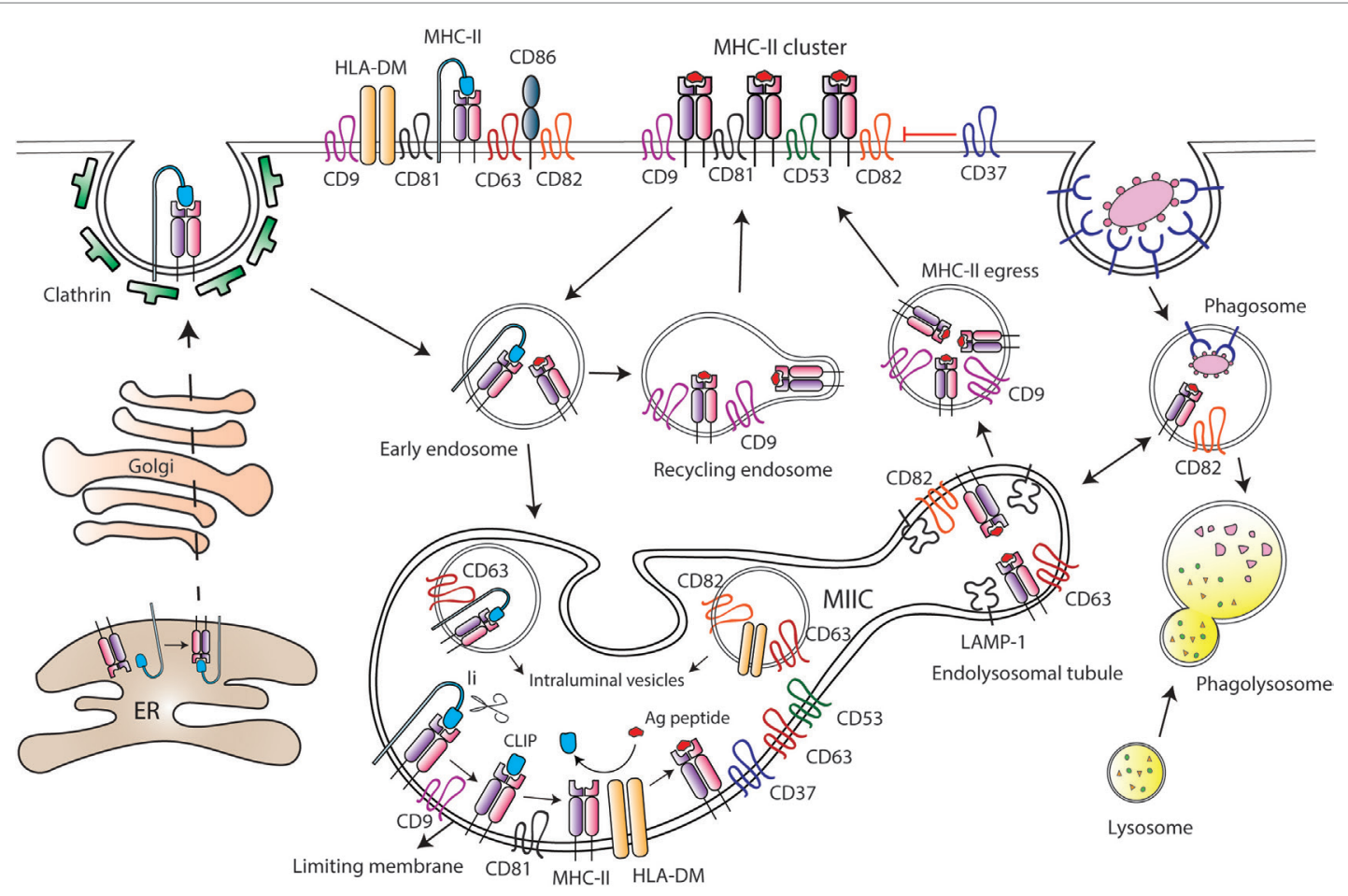

FIGURE 3 | Tetraspanins regulate major histocompatibility complex class II (MHC-II) trafficking and surface expression at antigen-presenting cells (APCs). After synthesis, MHC-II molecules are transported to the plasma membrane of APCs in association with the chaperone li, which drives MHC-II internalization through clathrin-coated pits. Then, li is sequentially degraded by different proteases at the MHC-II-enriched endosomal compartment (MIIC), until MHC-II molecules remain bound only to the CLIP (class II-associated invariant chain peptide) fragment. Peptides derived from internalized antigens are subsequently loaded to MHC-II molecules with the help of the class-II-like chaperone HLA-DM. Several tetraspanins are greatly enriched at the MIIC compartment, and peptide-bound MHC-II molecules coupled to li are included into tetraspanin-enriched microdomains (TEMs). Tetraspanin CD9 is required for the efficient egress of MHC-II from MIIC to the cell surface, and it is essential for MHC-II endocytosis and recycling. CD82 together with CD63 accumulate in LAMP-1-enriched endolysosomal tubules that emanate from the MIIC. In MIIC intraluminal vesicles, CD63 is associated with MHC-II and HLA-DM; while CD82 only interacts with HLA-DM. In addition, CD82 is preferentially associated with peptide-bound MHC-II, and it is found in phagosomes prior to their fusion with lysosomes. At the APC surface, tetraspanins CD9, CD53, CD81, and CD82 are associated with MHC-II, and tetraspanin CD37 negatively regulates MHC-II clustering. Moreover, TEMs containing CD9, CD63, CD81, and CD82 include MHC-II, HLA-DM, and CD86 molecules.

cholesterol content is essential for multimerization $(80,81)$. In addition, it was later demonstrated that the CDw78 determinant also recognizes peptide-bound MHC-II molecules coupled to the chaperone class-II associated invariant chain (Ii) (82). Intracellular trafficking of MHC-II molecules in APCs is a tightly regulated process, essential for proper antigen internalization, processing and subsequent presentation to T lymphocytes. Newly synthesized MHC II molecules associate with the chaperon Ii in the endoplasmic reticulum, which prevents premature peptide loading of MHC-II until MHCII-Ii complex enters the endocytic pathway (83) (Figure 3). The observation that peptide-bound MHC-II molecules coupled to the chaperone Ii (recognized by the CDw78 determinant) are included in $\operatorname{TEMs}(79,82)$ suggests that tetraspanins could regulate MHC-II trafficking at the MHC Class II compartment (MIIC). Accordingly, there is considerable evidence supporting this hypothesis.

The MIIC is a multilamellar compartment that has similarities with late endosomes, being enriched in classical late endocytic markers, like LAMP-1, and in resident proteases, like cathepsins (84-86). Several tetraspanins, including CD37, CD53, CD63, CD81, and CD82, are highly enriched at the MIIC of human
MoDCs and B cell lines (76, 87-89) (Figure 3). MHC-II diffusion rates are comparable to the diffusion values of CD63 and CD82, indicating inclusion into TEMs (89). Indeed, CD63 associates with MHC-II at both intraluminal vesicles and limiting membranes of the MIIC, and with the chaperone HLA-DM at the intraluminal vesicles. On the contrary, CD82 associates with HLA-DM at MIIC intraluminal vesicles and limiting membranes, but it only associates with MHC-II molecules at the limiting membrane $(88,89)$. CD82 would be mostly associated with peptide-bound MHC-II molecules, since it does not interact with MHC-II-coupled to Ii (88). Accordingly, CD82 and MHC-II are recruited together to phagosomes containing fungi or bacteria, before the fusion with lysosomes (90). Moreover, CD82 deficiency in DCs slightly reduces the maturation of $\mathrm{MHC}-\mathrm{II} /$ peptide complexes (72). However, despite abundant evidence that tetraspanins dynamically interact with MHC-II and HLA-DM at the MIIC, they do not seem to be essential for peptide loading to MHC-II molecules. Downregulation of CD9, CD63, CD81, and CD82 in human cell lines does not affect surface expression of peptide-bound MHC-II (89), and CD9 deficiency in BMDCs does not affect antigen proteolysis (91). The dynamic interactions between these molecules 
at the MIIC compartment would rather indicate that TEMs are important organizers of MHC-II trafficking in APCs.

After being loaded with antigenic peptides, MHC-II molecules egress from the MIIC to the APC surface, a process that remains largely undefined. Recently, it has been reported that tetraspanin CD9 is important for MHC-II egress to the surface of mouse immature MoDCs (91). CD9-deficient MoDCs display increased accumulation of MHC-II molecules in acidic compartments, in which MHC-II colocalizes with LAMP-1. As a consequence, surface expression of MHC-II is decreased in the absence of CD9 (91). Upon DC maturation, tubular extensions emanate from the MIIC in a process dependent on microtubules and microtubule-adaptor proteins (92-94), thus transporting peptide-bound MHC-II molecules to the plasma membrane $(95,96)$. In mouse BMDCs stimulated with LPS, these dynamic tubular extensions are enriched in LAMP-1 and tetraspanins CD63 and CD82 and show accumulation of fluorescent OVA protein (93) (Figure 3). In mature MoDCs, CD9 is not involved in MHC-II egress from the MIIC to the plasma membrane, which would take place only in a CD9-independent manner (91). Therefore, transport of peptide-bound MHC-II to the cell surface might be dependent on different TEMs, whose composition would be tightly controlled before and after cell maturation.

After arriving at the APC plasma membrane, peptide-bound MHCII molecules are actively endocytosed and then recycled back to the surface via early endocytic compartments. MHC-II endocytosis occurs through clathrin- and dynamin-independent pathway(s) (83). Early studies suggested that in immature DCs, MHC-II internalization is facilitated through ubiquitination by the ubiquitin E3 ligase MARCH-I $(97,98)$. MHC-II ubiquitination would be less efficient in mature DCs due to reduced MARCH-I expression, which would result in an increase in MHC-II surface expression $(98,99)$. However, subsequent studies have challenged this view (100-102). MHC-II ubiquitination enhances the kinetics of degradation of peptide-bound MHC-II molecules in immature DCs (101) and prevents recycling of internalized molecules back to the membrane (102), without affecting endocytosis. MHC-II recycling back to the surface is highly increased upon DC maturation, greatly contributing to boost MHC-II surface expression (102). Other members of the MARCH family have been shown to be involved in tetraspanin turnover. CD81 is targeted to lysosomes in the presence of MARCH-IV and -VIII, but not MARCH-I. Accordingly, MARCH-IV downregulation by siRNA increases CD81 surface expression (103). The effect of MARCH proteins on CD81 turnover could also affect the expression levels of CD81-interacting partners included in TEMs. Importantly, a recent study showed that CD9 is essential for MHC-II endocytosis in both immature and mature MoDCs, by a mechanism independent on MHC-II ubiquitination. Moreover, CD9 deficiency prevents MHC-II recycling in mature MoDCs (91). Tetraspanins are therefore important players in MHC-II trafficking and surface expression at APCs.

Tetraspanins are relevant for antigen presentation to $\mathrm{T}$ lymphocytes. Early studies have suggested that disruption of TEMs by cholesterol depletion, which is an essential component of these microdomains (104), affects the capacity of APCs to stimulate T cell activation $(79,81)$. However, cholesterol depletion can also disrupt lipid rafts, which are also required for proper antigen presentation (105). More recently, the specific functions of individual tetraspanins during antigen presentation have been established. CD37 negatively regulates $\mathrm{MHC}$-dependent antigen presentation to $\mathrm{CD}^{+}$and $\mathrm{CD}^{+} \mathrm{T}$ cells, while CD151 inhibits T-cell co-stimulation by mouse CD $11 c^{+}$splenic DCs. As a consequence, mouse deficiency in those tetraspanins triggers $\mathrm{CD}^{+}$and $\mathrm{CD}^{+} \mathrm{T}$-cell hyperstimulation (77). Sheng and collaborators have suggested that CD37 and CD151 could negatively regulate MHC clustering; however, despite the functional evidence demonstrated in their study, the molecular mechanisms behind CD37 and CD151 function remain to be determined. A similar phenotype was also observed with $\mathrm{Tssc}^{-/-}$and $\mathrm{CD} 37^{-1-} \mathrm{Tssc}^{-/-}$mice, through a mechanism independent on DC costimulatory signals (106). CD63 knock-down in human B cell lines also enhances MHC-IIdependent $\mathrm{CD} 4^{+} \mathrm{T}$ cell stimulation, but in this case, the mechanism seems to be related with increased production of extracellular vesicles (107). In this sense, T cell activation can be induced by extracellular vesicles derived from mature DCs $(18,108)$, which are enriched in MHC-I and MHC-II, and several tetraspanins, like CD9, CD63, CD81, and CD82 $(87,109)$. MHC-II sorting into extracellular vesicles has been suggested to depend on its recruitment to TEMs (110-112). Together, these data suggest negative roles for some tetraspanins during antigen presentation. However, other tetraspanins can have the opposite effect. Indeed, mouse $\mathrm{CD}^{-/-} \mathrm{MoDC}$ induce less $\mathrm{CD} 4^{+} \mathrm{T}$-cell activation and proliferation than wild-type MoDCs, due to reduced surface expression of MHC-II (91). Strikingly, CD9-deficient Flt3L conventional DC (cDC) showed similar T-cell stimulatory capacity as wild-type cDCs, triggering comparable $\mathrm{CD}^{+} \mathrm{T}$ proliferation in vivo (91). The role of CD9 in antigen presentation seems therefore to be DC subset-specific, and it would be interesting to investigate the molecular mechanisms behind this difference. CD9 interacts with MHC-II, and engagement of this tetraspanin with antibodies promotes the formation of antigen-dependent conjugates between human $\mathrm{CD} 14^{+}$monocytes and T cells (113). CD9 could also play a role in antigen presentation through extracellular vesicles, since both are found at the MIIC and exosomes from mature splenic mouse DC lines (114). Together, these studies indicate that the strength of antigen presentation by professional APCs can be tightly regulated by TEM composition, with some tetraspanins playing positive roles while others limit T-cell activation signals.

\section{Tetraspanins Define Distinct DC Subsets}

Dendritic cells can be classified in several subsets that differentially control the strength and duration of T-cell responses. The main populations that have been described are plasmacytoid DCs (pDCs) and cDCs, which can be divided into several subpopulations. Monocytes can also be precursors of different subsets of DCs found in different tissues in the steady state and can generate MoDCs during inflammatory reactions (61). Both human and mice individual DC subsets display different TEM composition (115). In addition, expression of specific tetraspanins can be modulated by DC differentiation and maturation. For instance, CD9 is differentially expressed on conventional and pDCs $(115,116)$.

Regarding cDCs, it has been suggested that they have a higher capacity to sense, process and present phagocytosed antigens to T cells than pDCs. cDCs are classified in two main subsets: CD141 ${ }^{+}$ $\left(\mathrm{BDCA}^{+}\right)$in humans and $\mathrm{CD} 8 \alpha^{+}\left(\mathrm{CD} 11 \mathrm{~b}^{-} \mathrm{CD} 11 \mathrm{c}^{+}\right)$in mice; or 
$\mathrm{CD}_{1} \mathrm{c}^{+}\left(\mathrm{BDCA}^{+}\right)$in humans and $\mathrm{CD}^{+}\left(\mathrm{CD} 11 \mathrm{~b}^{+} \mathrm{CD} 11 \mathrm{c}^{+}\right)$in mice $(3,4)$. Murine and human DC subsets have some similarities in their functional properties. In mice, $\mathrm{CD} 8 \alpha^{+} \mathrm{cDC}$ are found in lymphoid tissues and show similar phenotype and functional specialization to $\mathrm{CD} 103^{+} \mathrm{cDCs}$, which are found in non-lymphoid organs. Both subsets express comparable levels of TLRs, CLRs, and chemokine receptors and have a higher capability to cross-present antigens to $\mathrm{CD}^{+} \mathrm{T}$ lymphocytes compared to CD11b $\mathrm{b}^{+} \mathrm{DCs}(3)$. Interestingly, $\mathrm{CD} 141^{+}$human and $\mathrm{CD} 8 \alpha^{+}$mouse $\mathrm{CDCs}$ show high expression of tetraspanins CD9, CD53, and CD81 (115), which associate with MHC-I $(75,117)$. CD141 ${ }^{+} \mathrm{cDCs}$ also display high levels of CD37, CD82, CD151, and Tspan31 (115). The other main subset of $\mathrm{cDC}$ is $\mathrm{CD} 11 \mathrm{~b}^{+} \mathrm{cDCs}$, which seem to be more efficient in MHC-II-dependent antigen presentation to $\mathrm{CD}^{+} \mathrm{T}$ lymphocytes, thus triggering polarization to Th2 and Th17 responses (3). The tetraspanin expression profile was somewhat variable when comparing $\mathrm{CD}_{1} \mathrm{c}^{+}$human and $\mathrm{CD} 11 \mathrm{~b}^{+} \mathrm{CD} 11 \mathrm{c}^{+}$mouse $\mathrm{cDCs}$ (115). Indeed, $\mathrm{CD}^{+} \mathrm{c}^{+}$human $\mathrm{cDCs}$ express very high levels of CD37, CD53, and CD81 and display intermediate to high levels of $\mathrm{CD} 9, \mathrm{CD} 82$, and CD151. In mice, $\mathrm{CD} 4{ }^{+} \mathrm{CD} 11 \mathrm{~b}^{+} \mathrm{cDC}$ show intermediate to low levels of CD9, CD53, CD81, and CD151 (115). As previously discussed, several of these tetraspanins are described to regulate different steps of MHC-II trafficking and antigen presentation by APCs. However, further studies are necessary to ascertain whether specific tetraspanin expression profiles can be used as markers of $\mathrm{CDC}$ subsets and/or define APC functions.

Plasmacytoid DCs, both in humans and mice, have the capacity to produce large amounts of type I interferons (IFN- $\alpha / \beta)$ in response to invading pathogens $(118,119)$. pDCs $\left(\mathrm{BDCA}^{+}\right.$ in humans, and $\mathrm{B} 220^{+}$in mice) are a small subset, and in mice express low levels of MHC-II, co-stimulatory molecules, integrin CD11c, and PRRs (119). Importantly, tetraspanins can be used as markers for the identification of different mouse and human pDC subpopulations. CD9 expression allows the recognition of immature and mature mouse pDCs subsets. $\mathrm{CD}^{+}$Siglec- $\mathrm{H}^{\text {low }}$ pDCs have an immature phenotype, producing high levels of type I IFN and other pro-inflammatory cytokines. These cells are mainly present in mouse bone marrow and spleen, and when stimulated can induce strong $\mathrm{CD}^{+}$and $\mathrm{CD}^{+} \mathrm{T}$ cell responses in vitro and in vivo (120). In contrast, tissue resident $\mathrm{pDCs}$ are negative for $\mathrm{CD} 9$, do not produce IFN- $\alpha$, and have a tolerogenic phenotype, increasing the numbers of Foxp $3^{+} \mathrm{CD} 4^{+}$Treg cells in tumor-draining lymph nodes (120). Therefore, these two pDC subsets $\left(\mathrm{CD}^{+}\right.$and $\left.\mathrm{CD}^{-}\right)$define cells at different maturation stages at steady state. Upon infection, cell activation would induce migration of $\mathrm{CD}^{+} \mathrm{pDC}$ to the periphery, allowing the secretion of inflammatory cytokines at the infection site. Interestingly, upon maturation, $\mathrm{CD}^{+} \mathrm{pDC}$ upregulate markers of $\mathrm{pDC}$ differentiation but gradually lose CD9 expression (120). Distinct pDC mouse subsets can also be distinguished when looking at tetraspanin CD81. A small subpopulation of $\mathrm{B} 220^{+} \mathrm{CD} 5^{+} \mathrm{CD} 81^{+}$cells could be observed in blood, spleen, and bone marrow. This small subset does not produce IFN- $\alpha$, while splenic $\mathrm{CD}^{-} \mathrm{CD} 81^{-}$pDCs secrete high amounts of the cytokine (121). Similar CD81- and CD81 ${ }^{+}$ pDC subpopulations were observed in humans. Human pDCs are divided in two subsets depending on CD2 expression (122), and it has been recently demonstrated that $\mathrm{CD} 22^{\text {high }} \mathrm{pDCs}$ include
$\mathrm{CD} 2^{\text {hi }} \mathrm{CD}^{-} \mathrm{CD} 81^{-}$and $\mathrm{CD} 2^{\text {hi }} \mathrm{CD} 5^{+} \mathrm{CD} 81^{+}$cells $(121)$. Similarly to mice, human $\mathrm{CD} 2{ }^{\text {hi }} \mathrm{CD} 5^{+} \mathrm{CD} 81^{+} \mathrm{pDCs}$ represent a relatively rare subpopulation that produce little or no IFN- $\alpha$ (121). This subset can, however, secrete other pro-inflammatory cytokines, like IL-12p40 and IL-6, and is capable of inducing B-cell proliferation and differentiation to plasma cells. In addition, $\mathrm{CD} 2{ }^{\text {hi }} \mathrm{CD} 5^{+} \mathrm{CD} 81^{+}$ pDCs are efficient inducers of $\mathrm{CD} 4^{+} \mathrm{T}$ cell proliferation and Treg differentiation (121). Interestingly, antibodies against CD81 and CD9, but not CD63, specifically inhibited IFN- $\alpha$ production by pDCs when co-cultured with HCV-infected hepatoma cells. This effect was specifically related to CD81 expression in pDCs and required Rac GTPase activity (123). Hence, the absence of tetraspanins CD9 and CD81 seems to identify small pDC subpopulations that do not produce type I IFN. However, whether these tetraspanin expression profiles define overlapping pDC subsets and/or if differential expression of tetraspanins is associated with specific APC phenotypes remain to be determined.

\section{CONCLUSION}

In APCs, surface immune receptors and adhesion molecules, such as $\mathrm{MHC}$ molecules, co-receptors, PRRs, and integrins, associate with tetraspanins. Through the inclusion of these receptors in TEMs, tetraspanins can regulate their clustering, internalization, and intracellular trafficking, then affecting their downstream signaling. TEMs are thus important regulators of proper antigen uptake, processing and presentation. In addition, by modulating cytoskeleton-dependent processes, like outside-in integrin signaling, actin polymerization and cell spreading, tetraspanins are also key players in APC migration. Increasing evidence shows that different subsets of DCs having distinct requirements for antigen presentation and/or motility capabilities express specific repertoires of tetraspanins. This fine-tuned regulation warrants appropriate adaptive immune responses. Therefore, tetraspanins are potential targets for therapeutical interventions aiming to balance exaggerated immune responses in pathological inflammations and in immune-mediated chronic diseases.

\section{AUTHOR CONTRIBUTIONS}

MS and VR-P designed and wrote the review. VRP and FSM coordinated and edited the manuscript.

\section{ACKNOWLEDGMENTS}

We thank Dr Manuel Gomez-Gutierrez for critical reading and editing of the manuscript.

\section{FUNDING}

This work was supported by grants to FS-M (SAF2014-54705-R; SAF2017-82886-R; B2017/BMD-3671-INFLAMUNE; ERC2011-AdG 294340-GENTRIS; PIE13/00041; and CIBER CARDIOVASCULAR) and was co-funded by Fondo Europeo de Desarrollo Regional (FEDER). The CNIC is supported by the Spanish Ministry of Economy, Industry and Competitiveness (MINECO) and by the Pro CNIC Foundation. 


\section{REFERENCES}

1. Mogensen TH. Pathogen recognition and inflammatory signaling in innate immune defenses. Clin Microbiol Rev (2009) 22(2):240-273, Table of Contents. doi:10.1128/CMR.00046-08

2. Alvarez D, Vollmann EH, von Andrian UH. Mechanisms and consequences of dendritic cell migration. Immunity (2008) 29(3):325-42. doi:10.1016/j. immuni.2008.08.006

3. Merad M, Sathe P, Helft J, Miller J, Mortha A. The dendritic cell lineage: ontogeny and function of dendritic cells and their subsets in the steady state and the inflamed setting. Annu Rev Immunol (2013) 31:563-604. doi:10.1146/ annurev-immunol-020711-074950

4. Guilliams M, Ginhoux F, Jakubzick C, Naik SH, Onai N, Schraml BU, et al. Dendritic cells, monocytes and macrophages: a unified nomenclature based on ontogeny. Nat Rev Immunol (2014) 14(8):571-8. doi:10.1038/nri3712

5. Boucheix C, Rubinstein E. Tetraspanins. Cell Mol Life Sci (2001) 58(9): 1189-205. doi:10.1007/PL00000933

6. Hemler ME. Specific tetraspanin functions. J Cell Biol (2001) 155(7):1103-7. doi:10.1083/jcb.200108061

7. Charrin S, le Naour F, Silvie O, Milhiet PE, Boucheix C, Rubinstein E. Lateral organization of membrane proteins: tetraspanins spin their web. Biochem J (2009) 420(2):133-54. doi:10.1042/BJ20082422

8. Hemler ME. Tetraspanin functions and associated microdomains. Nat Rev Mol Cell Biol (2005) 6(10):801-11. doi:10.1038/nrm1736

9. Hemler ME. Tetraspanin proteins mediate cellular penetration, invasion, and fusion events and define a novel type of membrane microdomain. Annu Rev Cell Dev Biol (2003) 19:397-422. doi:10.1146/annurev.cellbio.19.111301. 153609

10. Yanez-Mo M, Barreiro O, Gordon-Alonso M, Sala-Valdes M, SanchezMadrid F. Tetraspanin-enriched microdomains: a functional unit in cell plasma membranes. Trends Cell Biol (2009) 19(9):434-46. doi:10.1016/j. tcb.2009.06.004

11. Barreiro O, Zamai M, Yanez-Mo M, Tejera E, Lopez-Romero P, Monk PN, et al. Endothelial adhesion receptors are recruited to adherent leukocytes by inclusion in preformed tetraspanin nanoplatforms. J Cell Biol (2008) 183(3):527-42. doi:10.1083/jcb.200805076

12. Espenel C, Margeat E, Dosset P, Arduise C, Le Grimellec C, Royer CA, et al. Single-molecule analysis of CD9 dynamics and partitioning reveals multiple modes of interaction in the tetraspanin web. J Cell Biol (2008) 182(4):765-76. doi: $10.1083 /$ jcb. 200803010

13. Rocha-Perugini V, Zamai M, Gonzalez-Granado JM, Barreiro O, Tejera E, Yanez-Mo M, et al. CD81 controls sustained T cell activation signaling and defines the maturation stages of cognate immunological synapses. Mol Cell Biol (2013) 33(18):3644-58. doi:10.1128/MCB.00302-13

14. Zuidscherwoude M, Gottfert F, Dunlock VM, Figdor CG, van den Bogaart G, Spriel AB. The tetraspanin web revisited by super-resolution microscopy. Sci Rep (2015) 5:12201. doi:10.1038/srep12201

15. Levy S, Shoham T. The tetraspanin web modulates immune-signalling complexes. Nat Rev Immunol (2005) 5(2):136-48. doi:10.1038/nri1548

16. Zoller M. Tetraspanins: push and pull in suppressing and promoting metastasis. Nat Rev Cancer (2009) 9(1):40-55. doi:10.1038/nrc2543

17. Jones EL, Demaria MC, Wright MD. Tetraspanins in cellular immunity. Biochem Soc Trans (2011) 39(2):506-11. doi:10.1042/BST0390506

18. Andreu Z, Yanez-Mo M. Tetraspanins in extracellular vesicle formation and function. Front Immunol (2014) 5:442. doi:10.3389/fimmu.2014.00442

19. Charrin S, Jouannet S, Boucheix C, Rubinstein E. Tetraspanins at a glance. J Cell Sci (2014) 127(Pt 17):3641-8. doi:10.1242/jcs.154906

20. Jiang X, Zhang J, Huang Y. Tetraspanins in cell migration. Cell Adh Migr (2015) 9(5):406-15. doi:10.1080/19336918.2015.1005465

21. Rocha-Perugini V, Sanchez-Madrid F, Martinez Del Hoyo G. Function and dynamics of tetraspanins during antigen recognition and immunological synapse formation. Front Immunol (2015) 6:653. doi:10.3389/fimmu.2015.00653

22. Termini CM, Gillette JM. Tetraspanins function as regulators of cellular signaling. Front Cell Dev Biol (2017) 5:34. doi:10.3389/fcell.2017.00034

23. Priyathilaka TT, Bathige S, Herath H, Lee S, Lee J. Molecular identification of disk abalone (Haliotis discus) tetraspanin 33 and CD63: insights into potent players in the disk abalone host defense system. Fish Shellfish Immunol (2017) 69:173-84. doi:10.1016/j.fsi.2017.08.020
24. Wu F, Su P, Chen L, Li M, Liu X, Li Q. Cloning of arctic lamprey Lethenteron camtschaticum cd9 with roles in the immune response. J Fish Biol (2012) 81(4):1147-57. doi:10.1111/j.1095-8649.2012.03299.x

25. Zhou X, Feng H, Guo Q, Dai H. Identification and characterization of the first reptilian CD9, and its expression analysis in response to bacterial infection. Dev Comp Immunol (2010) 34(2):150-7. doi:10.1016/j.dci.2009.09.001

26. LeBlanc F, Arseneau JR, Leadbeater S, Glebe B, Laflamme M, Gagne N. Transcriptional response of Atlantic salmon (Salmo salar) after primary versus secondary exposure to infectious salmon anemia virus (ISAV). Mol Immunol (2012) 51(2):197-209. doi:10.1016/j.molimm.2012.03.021

27. Castro R, Abos B, Gonzalez L, Aquilino C, Pignatelli J, Tafalla C. Molecular characterization of CD9 and CD63, two tetraspanin family members expressed in trout B lymphocytes. Dev Comp Immunol (2015) 51(1):116-25. doi:10.1016/j.dci.2015.03.002

28. Hou CY, Lin JH, Lin SJ, Kuo WC, Lin HT. Down-regulation of CD53 expression in Epinephelus coioides under LPS, poly (I:C), and cytokine stimulation. Fish Shellfish Immunol (2016) 51:143-52. doi:10.1016/j.fsi.2015.11.032

29. Song DH, Lee JO. Sensing of microbial molecular patterns by toll-like receptors. Immunol Rev (2012) 250(1):216-29. doi:10.1111/j.1600-065X.2012. 01167.x

30. Pfeiffer A, Bottcher A, Orso E, Kapinsky M, Nagy P, Bodnar A, et al. Lipopolysaccharide and ceramide docking to CD14 provokes ligandspecific receptor clustering in rafts. Eur J Immunol (2001) 31(11):3153-64. doi:10.1002/1521-4141(200111)31:11<3153::AID-IMMU3153>3.0. CO;2-0

31. Suzuki M, Tachibana I, Takeda Y, He P, Minami S, Iwasaki T, et al. Tetraspanin CD9 negatively regulates lipopolysaccharide-induced macrophage activation and lung inflammation. J Immunol (2009) 182(10):6485-93. doi:10.4049/ jimmunol.0802797

32. Witte CE, Archer KA, Rae CS, Sauer JD, Woodward JJ, Portnoy DA. Innate immune pathways triggered by Listeria monocytogenes and their role in the induction of cell-mediated immunity. Adv Immunol (2012) 113:135-56. doi:10.1016/B978-0-12-394590-7.00002-6

33. Martinez del Hoyo G, Ramirez-Huesca M, Levy S, Boucheix C, Rubinstein E, Minguito de la Escalera M, et al. CD81 controls immunity to Listeria infection through rac-dependent inhibition of proinflammatory mediator release and activation of cytotoxic T cells. J Immunol (2015) 194(12):6090-101. doi:10.4049/jimmunol.1402957

34. Taylor PR, Tsoni SV, Willment JA, Dennehy KM, Rosas M, Findon H, et al. Dectin-1 is required for beta-glucan recognition and control of fungal infection. Nat Immunol (2007) 8(1):31-8. doi:10.1038/ni1408

35. Mantegazza AR, Barrio MM, Moutel S, Bover L, Weck M, Brossart P, et al. CD63 tetraspanin slows down cell migration and translocates to the endosomal-lysosomal-MIICs route after extracellular stimuli in human immature dendritic cells. Blood (2004) 104(4):1183-90. doi:10.1182/blood2004-01-0104

36. Meyer-Wentrup F, Figdor CG, Ansems M, Brossart P, Wright MD, Adema GJ, et al. Dectin-1 interaction with tetraspanin CD37 inhibits IL-6 production. J Immunol (2007) 178(1):154-62. doi:10.4049/jimmunol.178.1.154

37. van Spriel AB, Sofi M, Gartlan KH, van der Schaaf A, Verschueren I, Torensma $\mathrm{R}$, et al. The tetraspanin protein CD37 regulates IgA responses and anti-fungal immunity. PLoS Pathog (2009) 5(3):e1000338. doi:10.1371/ journal.ppat.1000338

38. Yan J, Wu B, Huang B, Huang S, Jiang S, Lu F. Dectin-1-CD37 association regulates IL-6 expression during Toxoplasma gondii infection. Parasitol Res (2014) 113(8):2851-60. doi:10.1007/s00436-014-3946-1

39. Artavanis-Tsakonas K, Love JC, Ploegh HL, Vyas JM. Recruitment of CD63 to Cryptococcus neoformans phagosomes requires acidification. Proc Natl Acad Sci U S A (2006) 103(43):15945-50. doi:10.1073/pnas.0607528103

40. Huang W, Febbraio M, Silverstein RL. CD9 tetraspanin interacts with CD36 on the surface of macrophages: a possible regulatory influence on uptake of oxidized low density lipoprotein. PLoS One (2011) 6(12):e29092. doi:10.1371/ journal.pone.0029092

41. Heit B, Kim H, Cosio G, Castano D, Collins R, Lowell CA, et al. Multimolecular signaling complexes enable Syk-mediated signaling of CD36 internalization. Dev Cell (2013) 24(4):372-83. doi:10.1016/j.devcel.2013.01.007

42. Toyo-oka K, Yashiro-Ohtani Y, Park CS, Tai XG, Miyake K, Hamaoka T, et al. Association of a tetraspanin CD9 with CD5 on the T cell surface: role of 
particular transmembrane domains in the association. Int Immunol (1999) 11(12):2043-52. doi:10.1093/intimm/11.12.2043

43. Kaji K, Takeshita S, Miyake K, Takai T, Kudo A. Functional association of CD9 with the Fc gamma receptors in macrophages. JImmunol (2001) 166(5):3256-65. doi:10.4049/jimmunol.166.5.3256

44. Lebel-Binay S, Lagaudriere C, Fradelizi D, Conjeaud H. CD82, tetraspan-transmembrane protein, is a regulated transducing molecule on U937 monocytic cell line. J Leukoc Biol (1995) 57(6):956-63. doi:10.1002/ jlb.57.6.956

45. Wilflingseder D, Banki Z, Garcia E, Pruenster M, Pfister G, Muellauer B, et al. IgG opsonization of HIV impedes provirus formation in and infection of dendritic cells and subsequent long-term transfer to T cells. J Immunol (2007) 178(12):7840-8. doi:10.4049/jimmunol.178.12.7840

46. Peng WM, Yu CF, Kolanus W, Mazzocca A, Bieber T, Kraft S, et al. Tetraspanins CD9 and CD81 are molecular partners of trimeric FcvarepsilonRI on human antigen-presenting cells. Allergy (2011) 66(5):605-11. doi:10.1111/j.13989995.2010.02524.x

47. Halova I, Draber P. Tetraspanins and transmembrane adaptor proteins as plasma membrane organizers-mast cell case. Front Cell Dev Biol (2016) 4:43. doi:10.3389/fcell.2016.00043

48. Ding SW. RNA-based antiviral immunity. Nat Rev Immunol (2010) 10(9): 632-44. doi:10.1038/nri2824

49. Wang Y, Tong X, Omoregie ES, Liu W, Meng S, Ye X. Tetraspanin 6 (TSPAN6) negatively regulates retinoic acid-inducible gene I-like receptor-mediated immune signaling in a ubiquitination-dependent manner. J Biol Chem (2012) 287(41):34626-34. doi:10.1074/jbc.M112.390401

50. Ley K, Laudanna C, Cybulsky MI, Nourshargh S. Getting to the site of inflammation: the leukocyte adhesion cascade updated. Nat Rev Immunol (2007) 7(9):678-89. doi:10.1038/nri2156

51. Yanez-Mo M, Gutierrez-Lopez MD, Cabanas C. Functional interplay between tetraspanins and proteases. Cell Mol Life Sci (2011) 68(20):3323-35. doi:10.1007/s00018-011-0746-y

52. Dieu MC, Vanbervliet B, Vicari A, Bridon JM, Oldham E, Ait-Yahia S, et al. Selective recruitment of immature and mature dendritic cells by distinct chemokines expressed in different anatomic sites. J Exp Med (1998) 188(2):373-86. doi:10.1084/jem.188.2.373

53. Sozzani S, Allavena P, Vecchi A, Mantovani A. The role of chemokines in the regulation of dendritic cell trafficking. J Leukoc Biol (1999) 66(1):1-9. doi:10.1002/jlb.66.1.1

54. Sallusto F, Schaerli P, Loetscher P, Schaniel C, Lenig D, Mackay CR, et al. Rapid and coordinated switch in chemokine receptor expression during dendritic cell maturation. Eur J Immunol (1998) 28(9):2760-9. doi:10.1002/ (SICI) 1521-4141(199809)28:09<2760::AID-IMMU2760>3.0.CO;2-N

55. Sozzani S, Allavena P, D’Amico G, Luini W, Bianchi G, Kataura M, et al. Differential regulation of chemokine receptors during dendritic cell maturation: a model for their trafficking properties. JImmunol (1998) 161(3): $1083-6$.

56. Martin-Fontecha A, Sebastiani S, Hopken UE, Uguccioni M, Lipp M, Lanzavecchia A, et al. Regulation of dendritic cell migration to the draining lymph node: impact on T lymphocyte traffic and priming. J Exp Med (2003) 198(4):615-21. doi:10.1084/jem.20030448

57. Pileri P, Uematsu Y, Campagnoli S, Galli G, Falugi F, Petracca R, et al. Binding of hepatitis C virus to CD81. Science (1998) 282(5390):938-41. doi:10.1126/ science.282.5390.938

58. Nattermann J, Zimmermann H, Iwan A, von Lilienfeld-Toal M, Leifeld L, Nischalke HD, et al. Hepatitis C virus E2 and CD81 interaction may be associated with altered trafficking of dendritic cells in chronic hepatitis $\mathrm{C}$. Hepatology (2006) 44(4):945-54. doi:10.1002/hep.21350

59. Dijkstra S, Kooij G, Verbeek R, van der Pol SM, Amor S, Geisert EE Jr, et al. Targeting the tetraspanin CD81 blocks monocyte transmigration and ameliorates EAE. Neurobiol Dis (2008) 31(3):413-21. doi:10.1016/j.nbd.2008. 05.018

60. Schenk GJ, Dijkstra S, van het Hof AJ, van der Pol SM, Drexhage JA, van der Valk P, et al. Roles for HB-EGF and CD9 in multiple sclerosis. Glia (2013) 61(11):1890-905. doi:10.1002/glia.22565

61. Dominguez PM, Ardavin C. Differentiation and function of mouse monocytederived dendritic cells in steady state and inflammation. Immunol Rev (2010) 234(1):90-104. doi:10.1111/j.0105-2896.2009.00876.x
62. King IL, Dickendesher TL, Segal BM. Circulating Ly-6C+ myeloid precursors migrate to the CNS and play a pathogenic role during autoimmune demyelinatingdisease.Blood(2009)113(14):3190-7.doi:10.1182/blood-2008$07-168575$

63. Ko HJ, Brady JL, Ryg-Cornejo V, Hansen DS, Vremec D, Shortman K, et al. GM-CSF-responsive monocyte-derived dendritic cells are pivotal in Th17 pathogenesis. J Immunol (2014) 192(5):2202-9. doi:10.4049/jimmunol. 1302040

64. Barreiro O, Yanez-Mo M, Sala-Valdes M, Gutierrez-Lopez MD, Ovalle S, Higginbottom A, et al. Endothelial tetraspanin microdomains regulate leukocyte firm adhesion during extravasation. Blood (2005) 105(7):2852-61. doi:10.1182/blood-2004-09-3606

65. Feigelson SW, Grabovsky V, Shamri R, Levy S, Alon R. The CD81 tetraspanin facilitates instantaneous leukocyte VLA-4 adhesion strengthening to vascular cell adhesion molecule 1 (VCAM-1) under shear flow. J Biol Chem (2003) 278(51):51203-12. doi:10.1074/jbc.M303601200

66. Takeda Y, He P, Tachibana I, Zhou B, Miyado K, Kaneko H, et al. Double deficiency of tetraspanins $\mathrm{CD} 9$ and $\mathrm{CD} 81$ alters cell motility and protease production of macrophages and causes chronic obstructive pulmonary disease-like phenotype in mice. J Biol Chem (2008) 283(38):26089-97. doi:10.1074/ jbc.M801902200

67. Lammermann T, Bader BL, Monkley SJ, Worbs T, Wedlich-Soldner R, Hirsch K, et al. Rapid leukocyte migration by integrin-independent flowing and squeezing. Nature (2008) 453(7191):51-5. doi:10.1038/ nature 06887

68. Petrie RJ, Yamada KM. At the leading edge of three-dimensional cell migration. J Cell Sci (2012) 125(Pt 24):5917-26. doi:10.1242/jcs.093732

69. Wilson K, Lewalle A, Fritzsche M, Thorogate R, Duke T, Charras G. Mechanisms of leading edge protrusion in interstitial migration. Nat Commun (2013) 4:2896. doi:10.1038/ncomms3896

70. Quast T, Eppler F, Semmling V, Schild C, Homsi Y, Levy S, et al. CD81 is essential for the formation of membrane protrusions and regulates Rac1activation in adhesion-dependent immune cell migration. Blood (2011) 118(7):1818-27. doi:10.1182/blood-2010-12-326595

71. Tejera E, Rocha-Perugini V, Lopez-Martin S, Perez-Hernandez D, Bachir AI, Horwitz AR, et al. CD81 regulates cell migration through its association with Rac GTPase. Mol Biol Cell (2013) 24(3):261-73. doi:10.1091/mbc. E12-09-0642

72. Jones EL, Wee JL, Demaria MC, Blakeley J, Ho PK, Vega-Ramos J, et al. Dendritic cell migration and antigen presentation are coordinated by the opposing functions of the tetraspanins CD82 and CD37. J Immunol (2016) 196(3):978-87. doi:10.4049/jimmunol.1500357

73. Gartlan KH, Wee JL, Demaria MC, Nastovska R, Chang TM, Jones EL, et al. Tetraspanin CD37 contributes to the initiation of cellular immunity by promoting dendritic cell migration. Eur J Immunol (2013) 43(5):1208-19. doi:10.1002/eji.201242730

74. Angelisova P, Hilgert I, Horejsi V. Association of four antigens of the tetraspans family (CD37, CD53, TAPA-1, and R2/C33) with MHC class II glycoproteins. Immunogenetics (1994) 39(4):249-56. doi:10.1007/BF00188787

75. Szollosi J, Horejsi V, Bene L, Angelisova P, Damjanovich S. Supramolecular complexes of MHC class I, MHC class II, CD20, and tetraspan molecules (CD53, CD81, and CD82) at the surface of a B cell line JY. J Immunol (1996) 157(7):2939-46.

76. Engering A, Pieters J. Association of distinct tetraspanins with MHC class II molecules at different subcellular locations in human immature dendritic cells. Int Immunol (2001) 13(2):127-34. doi:10.1093/intimm/13.2.127

77. Sheng KC, van Spriel AB, Gartlan KH, Sofi M, Apostolopoulos V, Ashman L, et al. Tetraspanins CD37 and CD151 differentially regulate Ag presentation and T-cell co-stimulation by DC. Eur J Immunol (2009) 39(1):50-5. doi:10.1002/eji.200838798

78. Unternaehrer JJ, Chow A, Pypaert M, Inaba K, Mellman I. The tetraspanin CD9 mediates lateral association of MHC class II molecules on the dendritic cell surface. Proc Natl Acad Sci U S A (2007) 104(1):234-9. doi:10.1073/ pnas.0609665104

79. Kropshofer H, Spindeldreher S, Rohn TA, Platania N, Grygar C, Daniel N, et al. Tetraspan microdomains distinct from lipid rafts enrich select peptideMHC class II complexes. Nat Immunol (2002) 3(1):61-8. doi:10.1038/ ni750 
80. Khandelwal S, Roche PA. Distinct MHC class II molecules are associated on the dendritic cell surface in cholesterol-dependent membrane microdomains. J Biol Chem (2010) 285(46):35303-10. doi:10.1074/jbc.M110.147793

81. Bosch B, Heipertz EL, Drake JR, Roche PA. Major histocompatibility complex (MHC) class II-peptide complexes arrive at the plasma membrane in cholesterol-rich microclusters. J Biol Chem (2013) 288(19):13236-42. doi:10.1074/jbc.M112.442640

82. Poloso NJ, Denzin LK, Roche PA. CDw78 defines MHC class II-peptide complexes that require Ii chain-dependent lysosomal trafficking, not localization to a specific tetraspanin membrane microdomain. J Immunol (2006) 177(8):5451-8. doi:10.4049/jimmunol.177.8.5451

83. ten Broeke T, Wubbolts R, Stoorvogel W. MHC class II antigen presentation by dendritic cells regulated through endosomal sorting. Cold Spring Harb Perspect Biol (2013) 5(12):a016873. doi:10.1101/cshperspect.a016873

84. Calafat J, Nijenhuis M, Janssen H, Tulp A, Dusseljee S, Wubbolts R, et al. Major histocompatibility complex class II molecules induce the formation of endocytic MIIC-like structures. JCell Biol (1994) 126(4):967-77. doi:10.1083/ jcb.126.4.967

85. Honey K, Rudensky AY. Lysosomal cysteine proteases regulate antigen presentation. Nat Rev Immunol (2003) 3(6):472-82. doi:10.1038/nri1110

86. Roche PA, Furuta K. The ins and outs of MHC class II-mediated antigen processing and presentation. Nat Rev Immunol (2015) 15(4):203-16. doi:10.1038/ nri3818

87. Escola JM, Kleijmeer MJ, Stoorvogel W, Griffith JM, Yoshie O, Geuze HJ. Selective enrichment of tetraspan proteins on the internal vesicles of multivesicular endosomes and on exosomes secreted by human B-lymphocytes. J Biol Chem (1998) 273(32):20121-7. doi:10.1074/jbc.273.32.20121

88. Hammond C, Denzin LK, Pan M, Griffith JM, Geuze HJ, Cresswell P. The tetraspan protein $\mathrm{CD} 82$ is a resident of MHC class II compartments where it associates with HLA-DR, -DM, and -DO molecules. JImmunol (1998) 161(7):3282-91.

89. Hoorn T, Paul P, Janssen L, Janssen H, Neefes J. Dynamics within tetraspanin pairs affect MHC class II expression. J Cell Sci (2012) 125(Pt 2):328-39. doi: $10.1242 /$ jcs. 088047

90. Artavanis-Tsakonas K, Kasperkovitz PV, Papa E, Cardenas ML, Khan NS, Van der Veen AG, et al. The tetraspanin CD82 is specifically recruited to fungal and bacterial phagosomes prior to acidification. Infect Immun (2011) 79(3):1098-106. doi:10.1128/IAI.01135-10

91. Rocha-Perugini V, Martinez Del Hoyo G, Gonzalez-Granado JM, RamirezHuesca M, Zorita V, Rubinstein E, et al. CD9 regulates major histocompatibility complex class II trafficking in monocyte-derived dendritic cells. Mol Cell Biol (2017) 37(15):e202-17. doi:10.1128/MCB.00202-17

92. Wubbolts R, Fernandez-Borja M, Jordens I, Reits E, Dusseljee S, Echeverri C, et al. Opposing motor activities of dynein and kinesin determine retention and transport of MHC class II-containing compartments. J Cell Sci (1999) 112(Pt 6):785-95.

93. Vyas JM, Kim YM, Artavanis-Tsakonas K, Love JC, Van der Veen AG, Ploegh HL. Tubulation of class II MHC compartments is microtubule dependent and involves multiple endolysosomal membrane proteins in primary dendritic cells. J Immunol (2007) 178(11):7199-210. doi:10.4049/jimmunol. 178.11.7199

94. van Nispen tot Pannerden HE, Geerts WJ, Kleijmeer MJ, Heijnen HF. Spatial organization of the transforming MHC class II compartment. Biol Cell (2010) 102(11):581-91. doi:10.1042/BC20100046

95. Barois N, de Saint-Vis B, Lebecque S, Geuze HJ, Kleijmeer MJ. MHC class II compartments in human dendritic cells undergo profound structural changes upon activation. Traffic (2002) 3(12):894-905. doi:10.1034/j.16000854.2002.31205.x

96. Chow A, Toomre D, Garrett W, Mellman I. Dendritic cell maturation triggers retrograde MHC class II transport from lysosomes to the plasma membrane. Nature (2002) 418(6901):988-94. doi:10.1038/nature01006

97. Shin JS, Ebersold M, Pypaert M, Delamarre L, Hartley A, Mellman I. Surface expression of MHC class II in dendritic cells is controlled by regulated ubiquitination. Nature (2006) 444(7115):115-8. doi:10.1038/ nature 05261

98. van Niel G, Wubbolts R, Ten Broeke T, Buschow SI, Ossendorp FA, Melief CJ, et al. Dendritic cells regulate exposure of MHC class II at their plasma membrane by oligoubiquitination. Immunity (2006) 25(6):885-94. doi:10.1016/j. immuni.2006.11.001
99. De Gassart A, Camosseto V, Thibodeau J, Ceppi M, Catalan N, Pierre P, et al. MHC class II stabilization at the surface of human dendritic cells is the result of maturation-dependent MARCH I down-regulation. Proc Natl Acad Sci U S A (2008) 105(9):3491-6. doi:10.1073/pnas.0708874105

100. Matsuki Y, Ohmura-Hoshino M, Goto E, Aoki M, Mito-Yoshida M, Uematsu M, et al. Novel regulation of MHC class II function in B cells. EMBO J (2007) 26(3):846-54. doi:10.1038/sj.emboj.7601556

101. Walseng E, Furuta K, Bosch B, Weih KA, Matsuki Y, Bakke O, et al. Ubiquitination regulates MHC class II-peptide complex retention and degradation in dendritic cells. Proc Natl Acad Sci U S A (2010) 107(47):20465-70. doi:10.1073/pnas.1010990107

102. Cho KJ, Walseng E, Ishido S, Roche PA. Ubiquitination by march-I prevents MHC class II recycling and promotes MHC class II turnover in antigenpresenting cells. Proc Natl Acad Sci U S A (2015) 112(33):10449-54. doi:10.1073/pnas.1507981112

103. Bartee E, Eyster CA, Viswanathan K, Mansouri M, Donaldson JG, Fruh K. Membrane-associated RING-CH proteins associate with Bap31 and target CD81 and CD44 to lysosomes. PLoS One (2010) 5(12):e15132. doi:10.1371/ journal.pone.0015132

104. Charrin S, Manie S, Thiele C, Billard M, Gerlier D, Boucheix C, et al. A physical and functional link between cholesterol and tetraspanins. Eur J Immunol (2003) 33(9):2479-89. doi:10.1002/eji.200323884

105. Anderson HA, Hiltbold EM, Roche PA. Concentration of MHC class II molecules in lipid rafts facilitates antigen presentation. Nat Immunol (2000) 1(2):156-62. doi:10.1038/7784277842

106. Gartlan KH, Belz GT, Tarrant JM, Minigo G, Katsara M, Sheng KC, et al. A complementary role for the tetraspanins CD37 and Tssc6 in cellular immunity. J Immunol (2010) 185(6):3158-66. doi:10.4049/jimmunol.0902867

107. Petersen SH, Odintsova E, Haigh TA, Rickinson AB, Taylor GS, Berditchevski F. The role of tetraspanin CD63 in antigen presentation via MHC class II. Eur J Immunol (2011) 41(9):2556-61. doi:10.1002/eji.201141438

108. Tkach M, Kowal J, Zucchetti AE, Enserink L, Jouve M, Lankar D, et al. Qualitative differences in T-cell activation by dendritic cell-derived extracellular vesicle subtypes. EMBO J (2017) 36(20):3012-28. doi:10.15252/embj. 201696003

109. Thery C, Regnault A, Garin J, Wolfers J, Zitvogel L, Ricciardi-Castagnoli P, et al. Molecular characterization of dendritic cell-derived exosomes. Selective accumulation of the heat shock protein hsc73. J Cell Biol (1999) 147(3):599-610. doi:10.1083/jcb.147.3.599

110. Wubbolts R, Leckie RS, Veenhuizen PT, Schwarzmann G, Mobius W, Hoernschemeyer J, et al. Proteomic and biochemical analyses of human $\mathrm{B}$ cell-derived exosomes. Potential implications for their function and multivesicular body formation. J Biol Chem (2003) 278(13):10963-72. doi:10.1074/ jbc.M207550200

111. Saunderson SC, Schuberth PC, Dunn AC, Miller L, Hock BD, MacKay PA, et al. Induction of exosome release in primary B cells stimulated via CD40 and the IL-4 receptor. JImmunol (2008) 180(12):8146-52. doi:10.4049/ jimmunol.180.12.8146

112. Perez-Hernandez D, Gutierrez-Vazquez C, Jorge I, Lopez-Martin S, Ursa A, Sanchez-Madrid F, et al. The intracellular interactome of tetraspaninenriched microdomains reveals their function as sorting machineries toward exosomes. J Biol Chem (2013) 288(17):11649-61. doi:10.1074/jbc. M112.445304

113. Zilber MT, Setterblad N, Vasselon T, Doliger C, Charron D, Mooney N, et al. MHC class II/CD38/CD9: a lipid-raft-dependent signaling complex in human monocytes. Blood (2005) 106(9):3074-81. doi:10.1182/blood-200410-4094

114. Buschow SI, Nolte-'t Hoen EN, van Niel G, Pols MS, ten Broeke T, Lauwen M, et al. MHC II in dendritic cells is targeted to lysosomes or T cell-induced exosomes via distinct multivesicular body pathways. Traffic (2009) 10(10):1528-42. doi:10.1111/j.1600-0854.2009.00963.x

115. Zuidscherwoude M, Worah K, van der Schaaf A, Buschow SI, van Spriel AB. Differential expression of tetraspanin superfamily members in dendritic cell subsets. PLoS One (2017) 12(9):e0184317. doi:10.1371/journal.pone.0184317

116. Mittelbrunn M, Martinez del Hoyo G, Lopez-Bravo M, Martin-Cofreces NB, Scholer A, Hugues S, et al. Imaging of plasmacytoid dendritic cell interactions with T cells. Blood (2009) 113(1):75-84. doi:10.1182/blood-2008-02-139865

117. Lagaudriere-Gesbert C, Lebel-Binay S, Wiertz E, Ploegh HL, Fradelizi D, Conjeaud H. The tetraspanin protein CD82 associates with both free HLA 
class I heavy chain and heterodimeric beta 2-microglobulin complexes. J Immunol (1997) 158(6):2790-7.

118. Liu YJ. IPC: professional type 1 interferon-producing cells and plasmacytoid dendritic cell precursors. Annu Rev Immunol (2005) 23:275-306. doi:10.1146/ annurev.immunol.23.021704.115633

119. Swiecki M, Colonna M. The multifaceted biology of plasmacytoid dendritic cells. Nat Rev Immunol (2015) 15(8):471-85. doi:10.1038/nri3865

120. Bjorck P, Leong HX, Engleman EG. Plasmacytoid dendritic cell dichotomy: identification of IFN-alpha producing cells as a phenotypically and functionally distinct subset. J Immunol (2011) 186(3):1477-85. doi:10.4049/jimmunol. 1000454

121. Zhang H, Gregorio JD, Iwahori T, Zhang X, Choi O, Tolentino LL, et al. A distinct subset of plasmacytoid dendritic cells induces activation and differentiation of B and T lymphocytes. Proc Natl Acad Sci U S A (2017) 114(8):1988-93. doi:10.1073/pnas.1610630114

122. Matsui T, Connolly JE, Michnevitz M, Chaussabel D, Yu CI, Glaser C, et al. $\mathrm{CD} 2$ distinguishes two subsets of human plasmacytoid dendritic cells with distinct phenotype and functions. J Immunol (2009) 182(11):6815-23. doi:10.4049/jimmunol.0802008

123. Zhang S, Kodys K, Babcock GJ, Szabo G. CD81/CD9 tetraspanins aid plasmacytoid dendritic cells in recognition of hepatitis $C$ virus-infected cells and induction of interferon-alpha. Hepatology (2013) 58(3):940-9. doi:10.1002/ hep. 25827

Conflict of Interest Statement: The authors declare that the research was conducted in the absence of any commercial or financial relationships that could be construed as a potential conflict of interest.

Copyright $(2018$ Saiz, Rocha-Perugini and Sánchez-Madrid. This is an open-access article distributed under the terms of the Creative Commons Attribution License (CC BY). The use, distribution or reproduction in other forums is permitted, provided the original author(s) and the copyright owner are credited and that the original publication in this journal is cited, in accordance with accepted academic practice. No use, distribution or reproduction is permitted which does not comply with these terms. 